
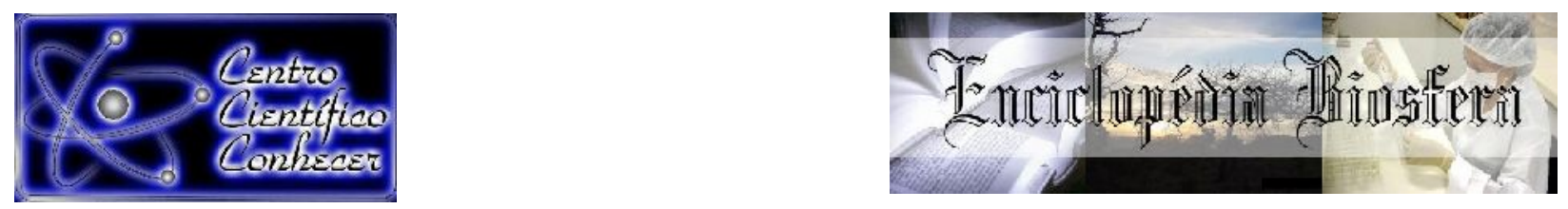

\title{
CARACTERIZAÇÃO DO PERFIL DOS PRODUTORES DE CULTIVOS ORGÂNICOS NA REGIÃO DE GOIÂNIA-GO
}

\author{
Victor Hugo Nascimento Neves ${ }^{1}$, Fernanda Rodrigues Vieira ${ }^{2}$, Francis Lee \\ Ribeiro ${ }^{3}$ \\ ${ }^{1}$ Bacharel em Agronomia pela Universidade do Federal de Goiás (UFG). \\ E-mail: victornascimento26@hotmail.com \\ 2 Doutoranda em Ciências Ambientais pelo Programa de Pós-Graduação em \\ Ciências Ambientais da Universidade Federal de Goiás (UFG). \\ E-mail: fernanda.vieira@discente.ufg.br \\ ${ }^{2}$ Professora Adjunta da Escola de Agronomia da Universidade Federal de \\ Goiás (UFG) . \\ E-mail: francis_lee@ufg.br
}

Recebido em: 15/11/2021 - Aprovado em: 15/12/2021 - Publicado em: 30/12/2021 DOI: 10.18677/EnciBio_2021D11

trabalho licenciado sob licença Creative Commons Attribution-NonCommercial-NoDerivatives 4.0 International License.

\begin{abstract}
RESUMO
Os impactos ambientais decorrentes das atividades econômicas em todo mundo tem impulsionado a utilização de sistemas sustentáveis, como por exemplo a produção orgânica de alimentos. Os cultivos orgânicos de gêneros alimentícios não utilizam agrotóxicos e se caracterizam por práticas agroecológicas e condizentes com a preservação da natureza. No Brasil, a agricultura orgânica ainda é pouco expressiva quando comparada com muitos países europeus, porém nos últimos anos vem apresentando um aumento gradativo de sua demanda. Na região de Goiânia-GO o mercado de alimentos orgânicos ainda é inexpressivo, formado por uma pequena e irregular oferta de produtos provenientes desse sistema. Em busca de entender a estrutura da oferta de produtos orgânicos o seguinte trabalho procurou caracterizar o perfil dos agricultores orgânicos que comercializam seus produtos nas principais feiras da capital. Para tanto, a pesquisa contou com levantamento bibliográfico para compreender o funcionamento da produção orgânica, em seguida elaborou-se um questionário que foi aplicado aos agricultores associados à Associação para o Desenvolvimento da Agricultura Orgânica em Goiás (ADAO-GO). A pesquisa foi realizada na região de Goiânia, com quinze produtores que se disponibilizaram a participar da entrevista. Os resultados obtidos mostram que os produtores possuem alto nível de escolaridade, áreas para produção menores do que 5 hectares, localizadas próximo a capital goiana. Outra característica evidenciada é o domínio dos agricultores quanto aos custos de produção e o fato de se sentirem bem remunerados nesse segmento.
\end{abstract}

PALAVRAS-CHAVE: Agricultura orgânica, feiras, produtores. 


\title{
CHARACTERIZATION OF THE PROFILE OF ORGANIC PRODUCERS IN THE GOIÂNIA REGION
}

\begin{abstract}
The environmental impacts resulting from economic activities around the world have driven the use of sustainable systems, such as organic food production. Organic food crops do not use pesticides and are characterized by agroecological practices that are consistent with the environment protection. In Brazil, organic agriculture is still not very expressive when compared to many European countries, but in recent years it has been showing a gradual increase in its demand. In the region of Goiânia-GO, the organic food market is still inexpressive, formed by a small and irregular offer of products from this system.In order to understand the structure of the offer of organic products, this study aimed to characterize the profile of organic farmers who sell their products at the main fairs in the capital. Therefore, the research included a bibliographic survey to understand the functioning of organic production, then a questionnaire was developed that was applied to farmers associated with the Association for the Development of Organic Agriculture in Goiás (ADAO-GO). The research was carried out in the region of Goiânia, with fifteen producers who made themselves available to participate in the interview. The results obtained show that producers have a high level of education, areas for production smaller than 5 hectares located near the capital of Goiás. Another characteristic evidenced is the domain of farmers in terms of production costs and the fact that they feel well paid in this segment of production.
\end{abstract}

KEYWORDS: Organic agriculture, fairs, producers.

\section{INTRODUÇÃO}

A agricultura moderna nos moldes tradicionais prioriza, principalmente, grandes proprietários de áreas agrícolas que adotam pacotes "tecnológicos" de multinacionais, compostos por insumos químicos, agrotóxicos e sementes geneticamente modificadas, voltadas para 0 aumento da produtividade $\mathrm{e}$ maximização de lucros. Tal formato contribui para o êxodo rural e desigualdade social no campo por parte dos produtores que não conseguem acompanhar essa dinâmica, que ao mesmo tempo em que aumenta a concentração de terra, amplia a disponibilidade de alimentos contaminados por agroquímicos (NODARI; GUERRA, 2015; CHABERT; SARTHOU, 2020).

Em meio às formas alternativas de utilização da terra, a produção orgânica é um sistema agropecuário originado de extrativismo sustentável que adota modelos compatíveis com os processos de agroecologia e diversidade de saberes locais. Este sistema é reconhecido pela não utilização de defensivos agrícolas em seus cultivos, já que além dos impactos ambientais, como contaminação da água e do solo, existe uma série de consequências para a saúde humana que vai desde intoxicações, mal-estar, dores de cabeça até o desenvolvimento de câncer (MAAS et al., 2020).

A agricultura orgânica se insere na ampla definição de desenvolvimento sustentável, uma vez que busca atender as necessidades da sociedade atual sem comprometer os recursos para as próximas gerações. Este sistema visa a produção consciente, que respeita os limites da natureza e estabelece uma relação harmônica da atividade econômica com a resiliência e equilíbrio dos ecossistemas (EMBRAPA, 2018). O cultivo orgânico possibilita o aumento da renda dos agricultores com menor custo de produção, maior margem de lucratividade e valorização do produto 
por parte de políticas públicas, como o Programa de Aquisição de Alimentos (PAA) e o Programa Nacional de Alimentação Escolar (Pnae), que oferece prêmios de $30 \%$ a mais para produtos oriundos de produção orgânica (COPELLO, 2016).

O perfil do consumidor de produtos orgânicos reflete o maior nível de escolaridade e de renda. Em estudos realizados por Avelar (2012), constatou-se que estes consumidores possuem renda familiar acima de cinco salários-mínimos. Lima (2015) relatou que $62 \%$ deste segmento, em Manaus, compravam os produtos por questões de saúde e de melhor qualidade de vida.

Nos países desenvolvidos tem crescido significativamente a demanda por produtos orgânicos, devido à busca por saúde, qualidade de vida e alimentos mais nutritivos. A atual geração possui maior exigência quanto ao tipo e qualidade dos alimentos que consomem (WILLER; LERNOUD, 2019). No Brasil o mercado de produtos orgânicos começou a ser expressivo a partir de 1990, com iniciativa de associações e cooperativas no País (COSTA et al., 2017). No entanto, a normatização ocorreu no ano de 2003 com a promulgação a Lei no 10.831 que trata sobre as formas de produção e de comercialização da produção orgânica no País.

\section{AGRICULTURA ORGÂNICA NO BRASIL}

Originado no final do século XIX na Europa, o movimento que deu origem à agricultura orgânica no mundo visava a alimentação natural e saudável que pudesse proporcionar melhor qualidade de vida à população, por meio de ideais da corrente de pensamento que contestava a forma de desenvolvimento industrial e urbano da época (VOGT, 2007). Este ideário apresentado sistematicamente no início de 1920 ganhou maior repercussão a partir da década de 1970, quando se tornaram mais relevantes as discussões sobre os impactos ambientais do desenvolvimento econômico (LIMA et al., 2019).

A agricultura orgânica atual representa a junção de diferentes correntes de pensamento, sendo: biodinâmica, biológica, natural, permacultura, ecológica, agroecológica, regenerativa e a agricultura sustentável, as quais possuem princípios semelhantes, tais como: a fertilidade natural do solo; diversificação e integração de explorações vegetais, incluindo as florestas e animais; adubação verde; controle biológico de pragas e fitopatógenos, com eliminação dos agrotóxicos; rotação e consorciação de culturas, entre outras que visam sempre a conservação e preservação dos recursos naturais (LEITE; POLLI, 2020).

Devido a capacidade em estabelecer técnicas agroecológicas, a produção orgânica se configura em um modelo de produção sustentável que visa principalmente conservação e ciclagem de nutrientes (SANDHU et al., 2010). Esse sistema de produção é fundamentado no uso da matéria orgânica e em fertilizantes minerais naturais a fim de manter a fertilização do solo. Suas implicações levam a compreender a interação do sistema produtivo com 0 meio ambiente, implementando práticas agrícolas sustentáveis, tais como controle biológico, plantio consorciado, manejo do solo, rotação de culturas e trofobiose das plantas, manter o equilíbrio do sistema, reduzir impactos ambientais (CHABERT; SARTHOU, 2020). Por não fazer uso de agrotóxicos no sistema de produção de orgânicos, ele oferece menores riscos à saúde humana e ao meio ambiente (MAAS et al., 2020).

Outro aspecto da sustentabilidade se deve ao fato de que a agricultura orgânica fortalece os pequenos agricultores, uma vez que o mercado oferece maiores prêmios aos produtos, melhor qualidade de vida para quem realiza os manejos, maior autonomia dos produtores rurais quanto a dependência de insumos agrícolas. O sistema exige mais mão de obra, permite se organizar por meio de 
associações e cooperativas, não faz o uso de agrotóxicos e possui menor custo de produção dos produtos (CAMPANHOLA; VALARINI, 2001). Gliessman (2001) enfatiza que o modelo de produção de orgânica além de incentivar pequenos agricultores rurais irem em busca de outro tipo de mercado, o mesmo fortalece o consumo regional desses produtos.

No Brasil o mercado de produtos orgânicos começou a ser expressivo a partir de 1990, com iniciativa de associações e cooperativas no País (COSTA et al., 2017). Nesse período não existia legislação brasileira para o segmento de produção orgânica, sendo que as certificadoras que estipulavam a própria normalização (COSTA et al., 2017). As primeiras normas da certificação orgânica no País foram estabelecidas pela Federação Internacional dos Movimentos da Agricultura Orgânica (IFOAM), que priorizava aspectos ambientais da produção e designava os insumos químicos permitidos (IFOAM, 2003). Somente em dezembro de 2003, veio a normatização com a Lei oㅜ 10.831, sobre a forma de produção e venda dos produtos (BRASIL, 2003; CANDIOTTO, 2018). A regulamentação ocorreu em 2007 por meio do Decreto no 6.323 (BRASIL, 2007). Após a regulamentação houve crescimento de $25 \%$ em média ao ano desde 2009, e movimentou três bilhões de reais somente no ano de 2016 (BACOCCINA, 2017).

Nos últimos anos no Brasil, segundo o Ministério da Agricultura, Pecuária e Abastecimento (MAPA, 2019), triplicou o número de produtores orgânicos cadastrados no Ministério da Agricultura. Esse aumento, como pode ser observado na Figura 1, ocorreu em função do crescimento do consumo de produtos orgânicos no País e devido ao aumento da exigência de regulamentação para a produção e comercialização. Os consumidores de orgânicos exigem informações sobre procedência dos produtos e garantia do selo de certificação fazendo com que os agricultores se regularizem junto ao órgão competente.

FIGURA 1. Número de produtores de cultivos orgânicos cadastrados no Ministério da Agricultura e Pecuária.

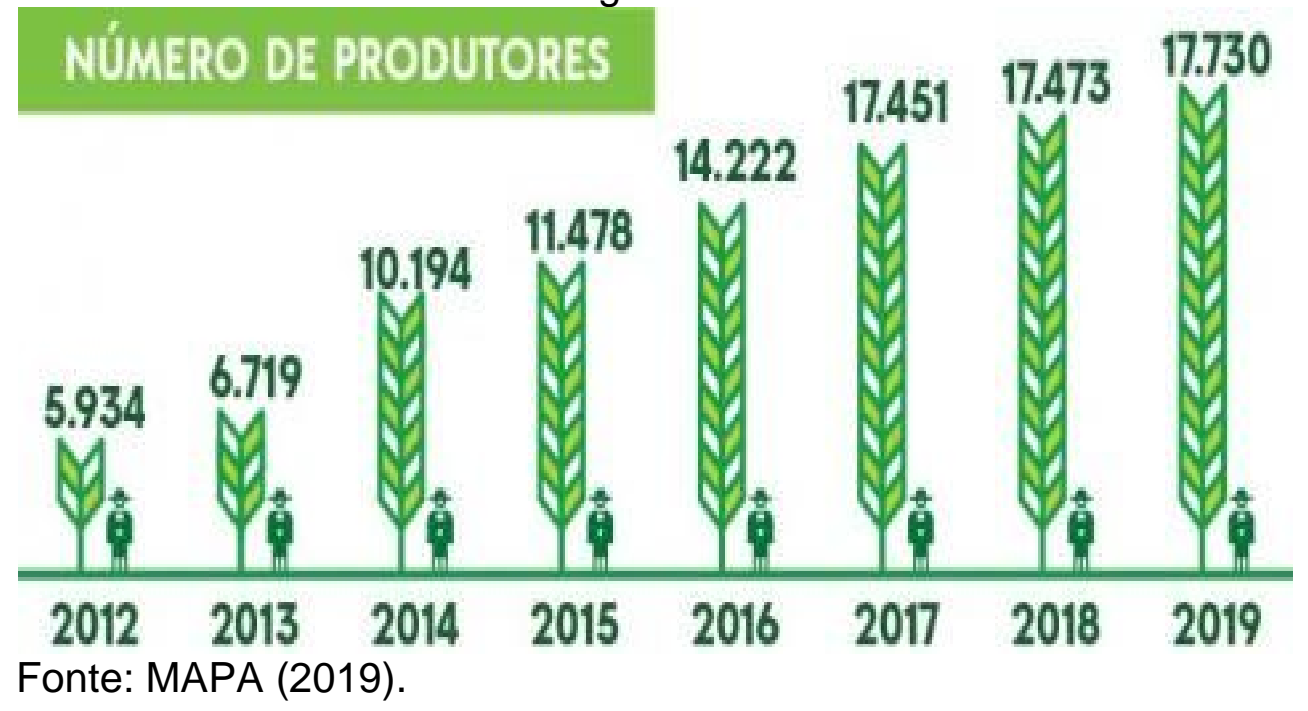

Em relação ao perfil dos agricultores de produtos orgânicos no Brasil, segundo pesquisa dirigida pelo Serviço de Apoio às Micro e Pequenas Empresas (SEBRAE, 2018), esses produtores tendem a se organizar em associações e também comercializam os produtos em canais direto ao consumidor, como por exemplo, as feiras. Vale ressaltar que agricultores com maior nível de escolaridade e instrução técnica detém maior esclarecimento sobre a importância e os benefícios 
da certificação, conforme foi demonstrado por Mazzoleni e Oliveira (2006). Já o período em que o produtor está inserido na produção orgânica revela que quanto maior esse tempo maior a experiência com o manejo dos cultivos, sendo que a certificação possuirá um papel relevante para a expansão desse mercado (MAZZOLENI; NOGUEIRA, 2006).

Considerando a importância do mercado de cultivos orgânicos para o estabelecimento de uma forma mais consciente de utilização da terra que envolve aspectos de sustentabilidade, o presente trabalho teve como objetivo principal caracterizar o perfil dos produtores de cultivos orgâncos que comercializam seus produtos nas principais feiras de Goiânia. Para tanto, a pesquisa levantou a seguinte questão: o que motiva os agricultores de orgânicos a realizar esse tipo de atividade? Para o cumprimento desse propósito, o trabalho está divido em uma sessão teórica que visa a compreensão dos principais conceitos relacionados à agricultura orgânica, uma sessão de métodos com a finalidade de esclarecer a forma como foi realizada a pesquisa, outra para a apresentação dos resultados e discussão e posteriormente, a conclusão com a sistematização dos resultados obtidos.

\section{MATERIAIS E MÉTODOS}

Para o cumprimento da primeira etapa da pesquisa realizou-se uma revisão bibliográfica por meio de livros, artigos científicos e documentos com a finalidade de compreender a produção orgânica, levando em consideração o ponto de vista social, ambiental e econômico. Foram identificadas as seguintes variáveis que auxiliaram na posterior elaboração do questionário:

- Variáveis sociais: origem da empresa rural, tamanho da propriedade, mão de obra que utiliza no estabelecimento, tecnologias empregadas, organização social de produção: (associação, cooperativa, sindicato); grau de formação e informação (assistência técnica) dos produtores.

- Variáveis ambientais: práticas e manejo agrícola (manejo integrado de Pragas, plantas daninhas, doenças e solo), produção diversificada, áreas de reserva legal (ARL), áreas de preservação permanente (APP).

- Variáveis econômicas: lucro, renda, produtividade, uso de insumos externos, custo de produção.

A pesquisa foi realizada em 2019, em Goiânia, com 15 produtores de orgânicos filiados a ADAO-GO (Associação para o Desenvolvimento da Agricultura Orgânica no Estado), de uma população de 60 agricultores associados. A amostra se deu por conveniência, com os associados que se disponibilizaram a participar das entrevistas e que estavam presentes nas feiras da capital. Aplicou-se o questionário nas três maiores feiras de produtos orgânicos em Goiânia, sendo: setor Europark, setor Vila Nova, setor Centro (Mercado da 74). Os questionários foram aplicados pelo autor principal desta pesquisa em uma amostra de $25 \%$ da população, uma vez que não seria possível entrevistar $100 \%$ dos produtores filiados, já que existe uma parcela de agricultores que não comercializam seus produtos nas feiras de orgânicos da capital goianiense e outra parcela de agricultores que não estavam presentes nos dias das entrevistas. A partir dos dados coletados foram realizadas análises descritivas com a elaboração de gráficos para melhor visualização dos resultados.

\section{RESULTADOS E DISCUSSÃO}

A amostra se constituiu por 15 agricultores $(\mathrm{N}=15)$ de produtos orgânicos que se disponibilizaram a responder o questionário desta pesquisa, sendo $53,33 \%(\mathrm{~N}=8)$ 
do sexo masculino e $46,67 \%(\mathrm{~N}=7)$ do sexo feminino. A faixa etária da amostra dos produtores pode ser vista na Figura 2, em que a maior porcentagem do grupo $(\mathrm{N}=5)$ situa-se na faixa de 26 a 35 anos, seguido pelo estrato de 36 a 45 anos $(N=4)$ e 56 a 65 anos ( $N=3$ ). Na cidade de Curitiba, Mazzoleni e Nogueira (2006), encontraram em seu trabalho que os produtores de cultivos orgânicos certificados possuíam média de idade de 40,3 anos, já os agricultores que estavam em processo de conversão possuíam média de 39,5 anos.

FIGURA 2: Distribuição da amostra de produtores orgânicos, por faixa etária, em feiras de produtos agroecológicos, na cidade de Goiânia, GO, (2019).

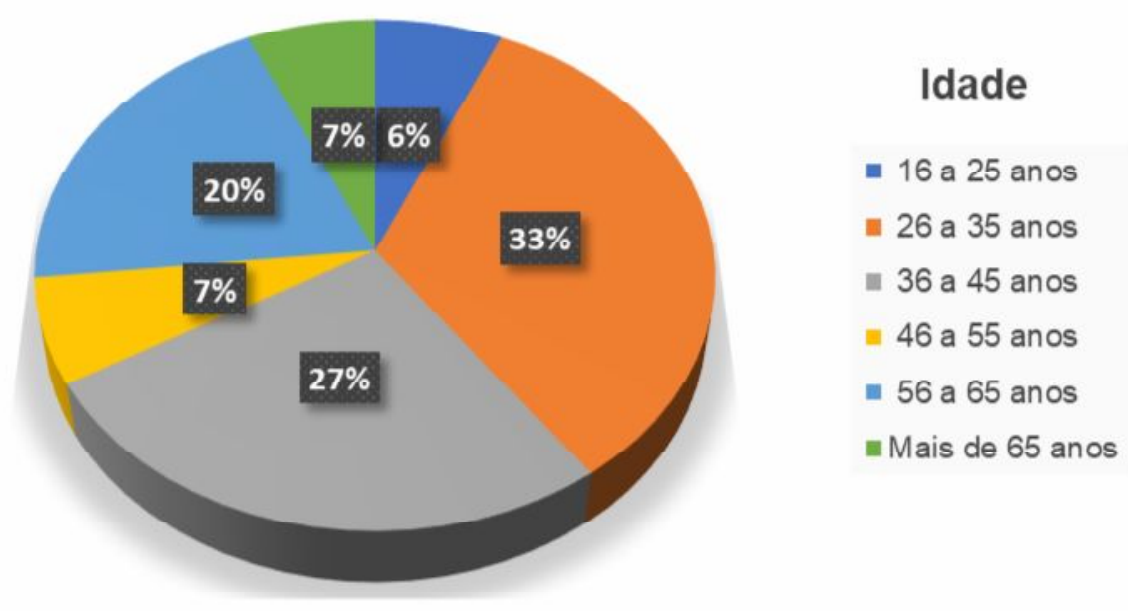

Fonte: Pesquisa de campo.

Quanto ao nível de escolaridade dos entrevistados, o maior grupo $(\mathrm{N}=8)$ apresenta ensino superior completo, seguido por profissionais que possuem curso superior e fizeram algum tipo de complemento $(\mathrm{N}=4)$, Lato Sensu, Stricto Sensu, ou Pós-Doutorado, e posteriormente por produtores que cursaram ao menos o ensino médio $(\mathrm{N}=3)$, conforme pode ser visto na Figura 3. Os autores Mazzoleni e Nogueira (2006) constataram em suas pesquisas que $46 \%$ dos agricultores certificados possuíam o nível superior e $27 \%$ cursaram até a $4^{a}$ série (Ensino Fundamental incompleto), já no grupo dos não certificados $15 \%$ cursaram o nível superior e $40 \%$ até a $4^{\underline{a}}$ série.

Em relação ao acesso à informação, todos fazem uso da internet para a obtenção de informações sobre o sistema de produção de orgânicos (artigos científicos, revistas, cursos e palestras). Para esses agricultores, a utilização de mídias sociais como Instagram, Facebook, WhatsApp têm sido cada vez mais necessária para a divulgação, comercialização e contato com clientes. 
FIGURA 3: Distribuição da escolaridade de produtores orgânicos, em feiras de produtos agroecológicos, na cidade de Goiânia, GO (2019).

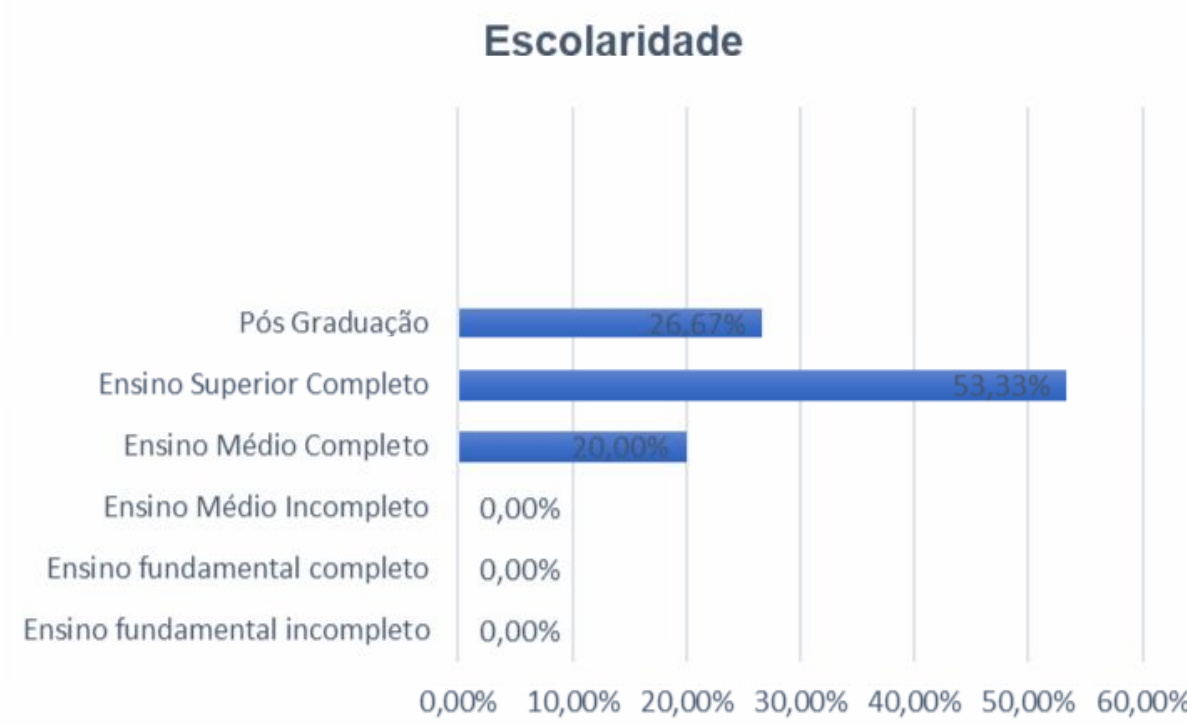

Fonte: Pesquisa de campo.

Quanto ao tempo de inserção dos produtores de cultivos orgânicos no campo, (Figura 4), observou-se que $26,67 \%$ dos entrevistados $(\mathrm{N}=4)$ possuem menos de cinco anos de trabalho no campo e $26,67 \%(\mathrm{~N}=4)$ possuem de cinco a 10 anos, ou seja, esses dois grupos somados retratam cerca de $53,34 \%$ da amostragem $(\mathrm{N}=8)$. Posteriormente vem o grupo que possui mais de 25 anos de trabalho no campo $(\mathrm{N}=3)$, seguido pelo de 10 a $15(\mathrm{~N}=2)$ anos e de 15 a 20 anos $(\mathrm{N}=2)$. Isso pode ser explicado pelo fato de que pessoas relativamente jovens e com instrução se interessam cada vez mais por atividades que permitem o restabelecimento da conexão do homem com a natureza.

FIGURA 4: Tempo de inserção do Produtor de produtos orgânicos com o campo, Goiânia, GO (2019).

\section{Tempo de inserção do Produtor de produtos orgânicos com o campo}

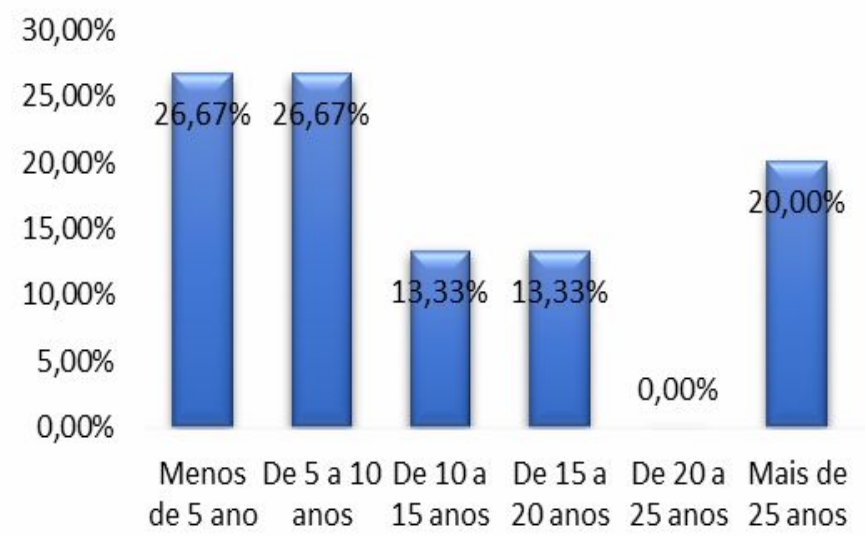

Fonte: Pesquisa de campo. 
O sistema de produção de cultivos orgânicos em Goiânia concentra-se em pequenos e médios empreendimentos que utilizam de mão-de-obra familiar ou de pequenos agricultores pertencentes à agricultura familiar. De acordo com os resultados dos questionários, $60 \% \quad(\mathrm{~N}=9)$ possuem menos de cinco hectares destinados à produção de cultivos orgânicos, enquanto $13,33 \%(\mathrm{~N}=2)$ possuem de cinco a 10 hectares, $13,33 \%(\mathrm{~N}=2)$ de 10 a 15 hectares e outros $13,33 \%(\mathrm{~N}=2)$ apresentam área acima de 25 hectares. Quanto ao número de pessoas que trabalham desde a produção até a fase final de comercialização, a maior parte do grupo se concentra entre três a quatro pessoas $(\mathrm{N}=7)$ de trabalhadores que participam na condução do sistema, seguido por um grupo de uma a duas pessoas $(\mathrm{N}=5)$, posteriormente outro grupo de quatro a cinco pessoas $(\mathrm{N}=2)$ e um dos entrevistados possuía de sete a oito pessoas $(\mathrm{N}=1)$.

A maior parte dos agricultores possuem suas áreas de produção em cidades vizinhas da capital goiana com um raio de até $100 \mathrm{Km}$ de distância, sendo que $26,67 \%(\mathrm{~N}=4)$ encontram-se em um raio de menos de $20 \mathrm{Km}, 40 \%(\mathrm{~N}=6)$ estão a uma distância entre 20 e $40 \mathrm{Km}, 20 \%(\mathrm{~N}=3)$ de 40 a $60 \mathrm{Km}, 6,67 \%(\mathrm{~N}=1)$ de 60 a 80 Kms e 6,67\% (N=1) de 80 a 100 Km de distância de Goiânia.

Os pesquisadores identificaram que estes agricultores estavam regulamentados e certificados com o selo e registro no Instituto Biodinâmico (IBID), uma vez que os produtos expostos nas feiras apresentavam os selos de identificação de produtos orgânicos conforme a normatização. Os agricultores são inscritos na Associação para o Desenvolvimento da Agricultura Orgânica do Estado de Goiás (ADAO-GO), fiscalizados por esta entidade, pelos próprios agricultores e pelos consumidores. Nesse sistema quanto maior a transparência de um produto agroecológico, livre de agrotóxicos e que atenda ao quesito de sustentabilidade, maior é a atratividade para os consumidores conforme foi relatado pelos próprios agricultores entrevistados.

Em relação aos motivos que levaram os agricultores a trabalhar com esse sistema de produção, constatou-se que grande parte dos entrevistados adota esse modelo de cultivo por questões de saúde $(\mathrm{N}=6)$. Foi relatado durante as entrevistas casos de intoxicação de produtores pelo uso de agrotóxicos na hora do manejo, o que levou os mesmos a fazerem a transição para o sistema de produção orgânica. Posteriormente, o segundo quesito mais relatado foi de caráter ambiental $(\mathrm{N}=4)$, em que os entrevistados demonstraram, em diversos níveis, preocupação com 0 impacto das atividades econômicas no meio ambiente.

Esse fato pode ser associado ao alto nível de informação e de escolaridade apresentada pelos agricultores e por divulgação dos meios de comunicação de alcance mundial para a transição de um modelo de produção e consumo mais sustentável, visando o equilíbrio com o meio social, ambiental e econômico. $\mathrm{O}$ quesito financeiro $(\mathrm{N}=3)$ foi apontado devido ao baixo custo de produção e maior prêmio agregado ao produto na hora da comercialização. Dessa forma, a produção orgânica acaba estimulando alguns agricultores a trabalharem nesse sistema pela recompensa financeira. Em seguida aparece o aspecto cultural e de tradição $(\mathrm{N}=2)$, já que muitos produtores de alimentos dão continuidade às atividades iniciadas pelos seus pais ou por membros de suas famílias.

Quanto à assistência técnica, os pesquisadores observaram que existe uma troca de informações sobre o sistema de cultivo entre os produtores associados à ADAO-GO. Dos entrevistados, $66,67 \%(\mathrm{~N}=10)$ disseram que utilizam assistência técnica para conduzir a produção, já outros $33,33 \%(\mathrm{~N}=5)$ disseram que não utilizam esse suporte. No entanto, deve ser levado em consideração que parte da 
amostragem que disse não usar assistência técnica são formados nos cursos de Engenharia Agronômica e são munidos de informações para condução da atividade. A assistência oferecida por um profissional técnico torna-se fundamental para que o sistema de produção siga as práticas agrícolas necessárias do manejo orgânico (BRASIL, 2011). Da mesma forma, o controle de custos faz-se imprescindível para o sucesso do empreendimento. Dos respondentes da pesquisa, 93,33\% ( $N=14)$ realizam esse tipo de controle enquanto $6,66 \%(\mathrm{~N}=1)$ não o faz.

Os resultados das pesquisas, (Figura 5), revelaram que 53,33\% (N=8) dos respondentes tem a lucratividade em torno dos $40 \%$. Outros $26,67 \%(\mathrm{~N}=4)$ disseram que a lucratividade está em torno de $20 \%$, enquanto $13,33 \%(\mathrm{~N}=2)$ relataram $30 \%$ de lucro, enquanto $6,67 \%(\mathrm{~N}=1)$ afirmou não possuir nenhum superávit. De acordo com Copello (2016), a produção orgânica permite maior retorno financeiro devido ao custo de produção ser menor, uma vez que não há necessidade de utilização de insumos químicos externos.

FIGURA 5: Margem de lucro da venda de produtos orgânicos, em feiras na cidade de Goiânia, GO, (2019).

\section{Margem de Lucro da venda de produtos orgânicos em Goiânia}

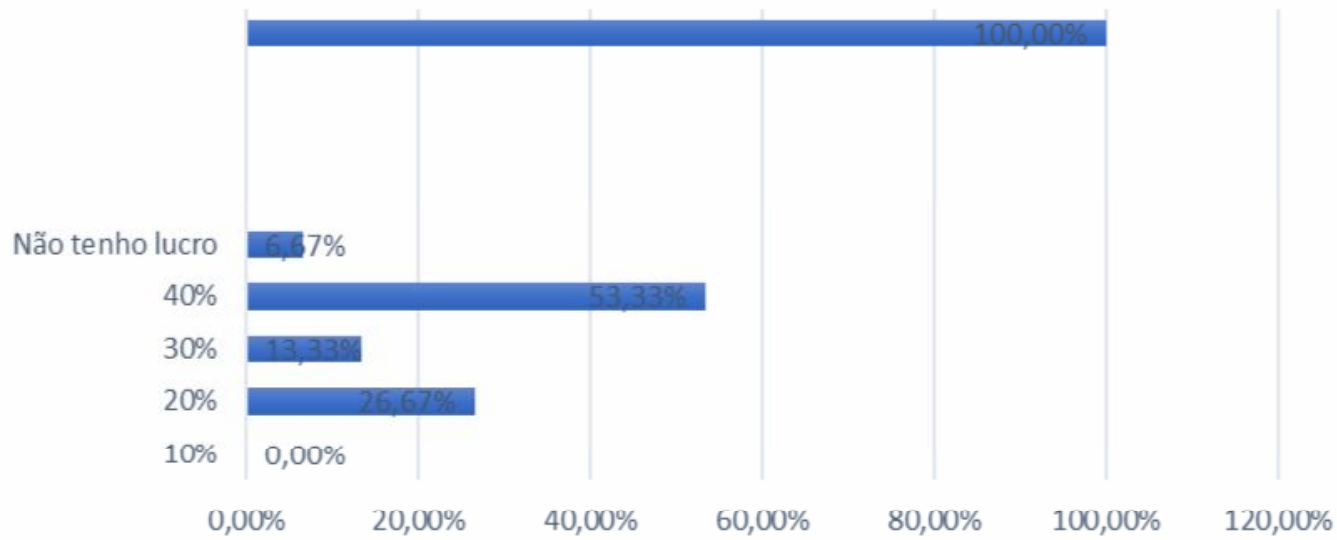

Fonte: Pesquisa de campo.

Segundo os resultados obtidos, $73,33 \% \quad(\mathrm{~N}=11)$ dos entrevistados fazem a comercialização de seus produtos em pelo menos duas feiras na cidade, sendo as mais relatadas a do setor Europark, setor Vila Nova e setor Central (Mercado da Rua 74), uma vez que são as feiras mais conhecidas na região de Goiânia. Não obstante, outras feiras estão surgindo com expressividade, como por exemplo, a feira da Universidade Federal de Goiás e a do Centro da Cidade, próximo a um bar elitizado da capital. Vale destacar que os demais produtores, $26,67 \%$ da amostra $(\mathrm{N}=4)$, frequentam mais de três feiras e realizam a comercialização de seus cultivos em outras cidades próximas à capital.

De acordo com entrevistados, a procura por produtos orgânicos na feira do Mercado da Rua 74 é maior do que nas demais localidades, em função da localização (local de fácil acesso, centro da capital), do horário (das 06:00 às 10:00 h) e do dia da semana (sábado no período da manhã). Porém, devem-se fazer estudos mais detalhados para compreender essas variáveis e como estas influenciam o comportamento dos consumidores. 
Os produtos oferecidos pelos produtores de orgânicos, segundo relatos dos respondentes, variam em qualidade e quantidade, de acordo com a época do ano. Os cultivos mais procurados têm sido hortaliças diversas, tomate, tubérculos, como cenoura, beterraba e batata doce, assim como feijão, ervilha e frutas da estação. Os preços dos produtos já são pré-estabelecidos entre os produtores comerciantes, de maneira que os preços são padronizados e não sofrem variações durante o decorrer da feira. De acordo com os resultados 73,33\% ( $\mathrm{N}=11)$ da amostra disseram não realizar a "Xepa", alimento que sobra da venda diária nas feiras-livres. Os outros $26,66 \%(\mathrm{~N}=4)$ dos comerciantes informaram vender um pouco abaixo do preço, com desconto, quando percebem que um ou outro produto está com característica visual não atrativa.

\section{CONCLUSÃO}

O presente trabalho teve como objetivo principal caracterizar o perfil dos produtores de cultivos orgânicos que comercializam seus produtos nas principais feiras de Goiânia. O perfil dos agricultores entrevistados é formado de maioria jovem, alto nível de escolaridade e com áreas para produção menores do que cinco hectares, localizadas próximo ao centro da capital goiana. Estão inseridos há menos de 10 anos no campo e possuem alto nível de informação sobre condução e manejo do sistema de produção orgânico. Outra característica evidenciada é o domínio dos agricultores quanto aos custos de produção e a satisfação que possuem em relação à remuneração da atividade.

Os resultados obtidos pelos pesquisadores permitiram observar que uma parcela expressiva dos agricultores associados à $A D A O-G O$ não realiza a comercialização dos seus produtos nas feiras agroecológicas de Goiânia, vendendo por meio de delivery, entrega direta ao consumidor, e para intermediários: supermercados, empórios e restaurantes da região. Como sugestão para as próximas pesquisas no segmento de orgânicos, pode-se investigar os impactos da pandemia de coronavírus sobre os canais de distribuição dos produtos, assim como o aumento da demanda devido às questões relacionadas à saúde e bem-estar dos indivíduos.

\section{REFERÊNCIAS}

AVELAR, E. A.; REIS, R. P.; SOUZA, A. A. Análise do Consumidor de Alimentos Orgânicos de Belo Horizonte - MG. In: XXXVI Encontro da ANPAD. Anais... Rio de Janeiro: ANPAD, 2012.

BACOCCINA, D. O dilema dos orgânicos. Plant Project, ed. 05, jul./ago. p. 28-35, 2017.

BRASIL. Lei no 10831, de 23 de dezembro de 2003. Estabelece norma para produção de produtos orgânicos vegetais e animais. Diário oficial da União, Brasília, seção 1, p. 8, 24 de dezembro de 2003.

BRASIL. Decreto de regulamentação da produção orgânica. 2007. Disponível em: https://ciorganicos.com.br. Acesso em: 01 nov. 2020.

BRASIL. Ministério da Agricultura, Pecuária e Abastecimento. Instrução Normativa no 46 de 06 de outubro de 2011. Disponível em: http://www.agricultura.gov.br. Acesso em: 12 de janeiro de 2020. 
CANDIOTTO, L. Z.; Organic products policy in Brazil. Land Use Policy, [S. I.], v. 71, n. October 2017, p. 422-430, 2018. Disponível em: <https://doi.org10.1016/j.landusepol.2017.12.014>. Acesso em 10 abr. 2019.

CAMPANHOLA, C.; VALARINI, P. J. A agricultura orgânica e seu potencial para o pequeno agricultor. Cadernos de Ciência \& Tecnologia, v. 18, n. 3, p. 69-101, 2001.

CHABERT, A.; SARTHOU, J. P. Conservation agriculture as a promising trade-off between conventional and organic agriculture in bundling ecosystem services. Agriculture, Ecosystems and Environment, [S. I.], v. 292, n. July 2019, p. 106815, 2020. Disponível em: https://doi.org/10.1016/j.agee.2019.106815. Acesso em: 20 fev. 2021.

COPELLO, C.; Produto agroecológico cada vez mais presente na mesa do consumidor. Revista Ênfase, v.1, p.6-7, 2016.

COSTA, M. B. B. da; SOUZA, M.; MÜLLER JÚNIOR, V.; COMIN, J. J.; LOVATO, P. E. Agroecology development in Brazil between 1970 and 2015. Agroecology and Sustainable Food Systems, v. 41, n.3-4, p.276-295, 2017.

EMBRAPA. Objetivos de Desenvolvimento Sustentável (ODS). 2018. Disponível em: https://www.embrapa.br/. Acesso em: 28 nov. 2020.

GLIESSMAN, S. R. Agroecologia: processos ecológicos em agricultura sustentável. Porto Alegre: Editora da Universidade Federal do Rio Grande do Sul, UFRGS, Porto Alegre. 653p, 2001.

IBGE. Instituto Brasileiro de Geografia e Estatistica. Censo Agropecuário 2006. Rio de Janeiro: IBGE, 2009.

IFOAM. International Federation of Organic Agriculture Movements. Normas para la producción y processado orgánico. 2003. Disponível em: https://www.ifoam.bio/. Acesso em: 28 nov. 2020.

LEITE, A. B.; POLLI, H. Q. Agricultura orgânica no Brasil com enfoque na agricultura biodinâmica. Interface Tecnológica, v.17, n. 1, 2020. Disponível em: $<$ https://doi.org/10.31510/infa.v17i1.787.

LIMA, P. F. C.; LIMA, A. M. M. LIMA; CASTRO, S. M. V.; GOMES, M. V. C. O consumo de alimentos orgânicos na cidade de Manaus (AM): o comércio de produtos e a sustentabilidade do setor. Revista Verde, Pombal, v. 10, n.1, p. 120$127,2015$.

LIMA, S. K.; GALIZA, M.; VALADARES, A.; ALVES, F. Produção e consumo de produtos orgânicos no mundo e no brasil. Texto para discussão / Instituto de Pesquisa Econômica Aplicada, [S. I.], p. 52, 2019. Disponível em: http://www.ipea.gov.br/portal/publicacoes. Acesso em: 15 jan. 2020. 
MAAS, L.; MALVESTITI, R.; GONTIJO, L. A.; O reflexo da ausência de políticas de incentivo à agricultura urbana orgânica: um estudo de caso em duas cidades no Brasil. Caderno Saúde Pública, v. 36, n.8, p. 1-12, 2020. Disponível em: <https://doi.org/10.1590/0102-311X00134319>. Acesso em: 19 nov. 2020.

MAPA. Ministério da Agricultura, Pecuária e Abastecimento. Em 7 anos, triplica o número de produtores orgânicos cadastrados no Ministério da Agricultura Brasília: MAPA, 2019. Disponível em: https://www.gov.br/. Acesso em: 12 de janeiro de 2020.

MAZZOLENI, E. M.; OLIVEIRA, L. G. Inovação tecnológica na agricultura orgânica: estudo de caso da certificação do processamento pós-colheita. Revista de Economia e Sociologia Rural. Piracicaba, SP, v. 48, n. 3, p. 567-586, 2010.

NODARI, R.; GUERRA, M. P. Agroecologia: estratégias de pesquisa e valores. Estudos avançados, v. 29, n.83, p.183-207, 2015. Disponível em: <https://doi.org/10.1590/S0103-40142015000100010 >. Acesso em 2 mar. 2019.

SANDHU, H. S; WRATTEN, S. D.; CULLEN, R. Review: Organic agriculture and ecosystem services. Environmental Science \& Policy, v. 1, n. 3, p. 1-7, 2010. Disponível em: < https://doi.org/10.1016/j.envsci.2009.11.002. Acesso em: 10 jan. 2021.

SEBRAE. Serviço de Apoio às Micro e Pequenas Empresas ; Pesquisa realizada pelo Sebrae com produtores orgânicos mostra como se organiza o setor no Brasil, 2018. Disponível em: <sebrae.com.br/sites/PortalSebrae/artigos>. Acesso em: 10 jul. 2021.

VOGT, G. The origins of organic farming. In: LOCKERETZ, W. (Ed.). Organic farming: an internacional history. Oxfordshire: CAB Internacional, p. 558, 2007.

WILLER, H.; LERNOUD, J. (Eds.). The world of organic agriculture: statistics and emerging trends 2019. Frick: FiBL; Bonn: Ifoam - Organics Internacional, 2019. 